\title{
ANTIQUITY
}

stones much damaged by ploughing. A larger round house, about $1 \mathrm{I} \cdot 0 \mathrm{~m}$. in diameter, had a wall of stakes, presumably supporting wickerwork, and an inner ring of large, deep postholes to hold the main roof supports. Another structure probably attributable to the Iron Age was marked by a rectangular setting, $5.0 \mathrm{~m}$. by $4.0 \mathrm{~m}$., of exceptionally large posts, up to $0.40 \mathrm{~m}$. in scantling. This building, virtually on the summit of the hill, and surrounded by pits containing carefully buried horse and ox skulls, suggests a timber shrine.

Evidence has accumulated during previous seasons that the native occupation of the hillfort ended in fire and the sword at the Roman Conquest. It appeared that the surviving inhabitants were removed from the fort, and it was believed that the Romans themselves had made no use of it. This hypothesis must now be abandoned because this season, in an area which had already yielded Roman military equipment, the wall-trenches of a prefabricated rectangular building of timber were found. A hobnail from one of the wall-trenches confirms the suggestion of the plan and constructional technique, that this was a Roman military building.

In another area on the summit ridge, part of a structure belonging to the post-Roman, 'Arthurian', occupation was uncovered. The cutting in question yielded an unusual quantity of imported 6th-century pottery of Tintagel type, most of it scattered in top soil, some of it from a pit, and two sherds from the filling of the wall-trench of one side of a rectangular building. These two sherds were noticeably less weathered than the others from the cutting. Among those too timid to grasp the Arthurian nettle, or too ill-informed about the 6th century $\mathrm{AD}$, much ingenuity has been, and will be, expended to explain these sherds away; but the most natural explanation for their condition and stratification is that they were tamped into the filling of the trench shortly after their parent vessel had been broken. In other words, they date the building. This season only one wall, most probably a gable end, was uncovered. The full exploration of this building must be a major objective in Ig69.

Looking ahead to the coming season, we may say this. Among the many medium to large hillforts of southern Britain, South Cadbury Castle has three unusual features: extensive traces of Early Neolithic settlement; 'Arthurian' defences and buildings; and the Late Saxon burh. About the defences and gates of the latter we now have plentiful information; and short of discovering, most probably by happy chance, the Aethelredan mint we do not expect to learn much more about this period. But in the case of the Neolithic and 'Arthurian' periods, we are at present merely on the brink of important discoveries. Determining the full limits of the Neolithic settlement, and exploring the structure of which one corner was found in 1967 , uncovering the 'Arthurian' building on the summit ridge, and exploring the contemporary gateway: these are four important objectives in themselves, but they are underlaid by the need for greater knowledge of the long, rich and complex later Bronze Age and Iron Age history. Given adequate resources, the final seasons at South Cadbury promise to be unusually rewarding.

LESLIE ALCOCK

\section{A Foundation Sacrifice at Birkenhead Priory}

The following note was sent to us by Mrs Nora $F$. McMillan of the Fane Herdman Laboratories of Geology of the University of Liverpool. It was written some years ago, shortly before $\mathrm{Mr} \mathrm{Fer}$ gusson Irwin's death at the age of 93 .

Birkenhead Priory, a Benedictine monastery founded in 1150 , was presented to Birkenhead Corporation in 1896 when also a careful restoration of the surviving building was made. The work of restoration was carried out by G. W. Haswell of Chester under the supervision of E. W. Cox and a full account was published by A. M. Robinson (1905). Yet the finding of animal bones in a carefully prepared cavity at the foot of one of the buttresses has not been recorded, save ephemerally and incorrectly in a local newspaper (Robinson I898).

The bones in question are preserved in the 


\section{NOTES AND NEWS}

Williamson Art Gallery and Museum, Birkenhead, and by courtesy of the Curator, $\mathrm{Mr} \mathrm{G}$. Stratton, were borrowed for examination. The only information concerning them is the statement of Robinson ( 1898 ), 'In the course of this work of restoration, in one of the buttresses was discovered a cavity wherein were the bones of a kid with a skull and horns complete. The stones were all properly faced inside, showing that the cavity had been intentionally built.'

The bones, however, are not those of a kid, but the incomplete skeleton of an adult (but not aged) sheep of a small and unimproved type. The bones present are the skull and both mandibles, pelvic girdle, sacrum, right femur, right tibia, right humerus, a scapula, and numerous ribs. Accompanying them is a fragment of a femur of Bos sp. (young) and a rabbit. These two latter are clearly extraneous and were probably picked up from the debris excavated at the time of restoration and in error added to the bones found in the cavity. In this Dr J. W. Jackson, who has examined the bones and confirmed their identification as those of sheep, with the two exceptions noted above, agrees.

The senior author was present during the restoration of Birkenhead Priory, and is now (February 1962) the only surviving eyewitness of the discovery of the cavity and the contained bones. His account of the find is given in his own words (19th November 1960) 'Of course I remember the kid's bones. Right in under the south-west buttress of the Prior's House and three feet below the floor there was a little aumbry-like hole about 24 in. long and I 8 in. high, very nicely and carefully made with a plain roll moulding round it. It must have been closed by a slab or door but I do not remember seeing one. Inside, lying in a little heap on the bottom of the "aumbry" was a little pile of bones which was diagnosed as the skeleton of a kid. I cannot exactly remember whether I saw them "in situ" or in a safe place nearby and was told of the find by the excavators. I think the former. Anyway, everybody knew about it at the time and, naturally, I was constantly in and out of the Priory during the whole of the restoration.'

The Williamson Art Gallery and Museum also possess an album of photographs showing in detail the work of restoration of the Priory and including a photograph of the bones, and also one of the aumbry-like cavity in which they were found.

It seems clear that the sheep was deliberately immured in the recess prepared for it, and whether or not this constitutes a genuine example of a foundation sacrifice the facts are here recorded.

W. FERGUSSON IRWIN and N. F. MCMILLAN

\section{BIBLIOGRAPHY}

robinson, A. M. 1898. 'The Old Priory at Birkenhead. An interesting Reminiscence', Birkenhead and Cheshire Advertiser and Wallasey Guardian, $15^{\text {th January } 1898 .}$

1905. 'The Birkenhead Priory Reparation', Transactions of the Historical Society of Lancashire and Cheshire, LV/LVI (New Series vols. 19/20), 107.

\section{Air Reconnaissance: Recent Results, I6}

PLATE VIII

The archaeology of Ireland has until recently been little explored from the air. Part of the country has been photographed in the search for raw materials, and to assist town and country planning. But, survey photography at scales of I : 10,000 or less, taken within a few hours of midday is not designed to record small earthworks, and crop-marks often pass unnoticed. Until recently an assessment of the value of air photography as a method of research in Ireland has hardly been possible [I].
During the last six years widely ranging reconnaissance of Ireland has been undertaken by the Committee for Aerial Photography of the University of Cambridge, the flights being planned for research. In the light of this work a clearer picture emerges of the results to be expected from the application of air photography to Irish archaeology. Compared with England a far greater proportion of the country is under permanent pasture, and for this reason, minor earthworks of all periods from the Bronze Age 